\title{
Porainu kvartāra mālu keramikas granulu sorbcijas īpašības
}

\author{
Ruta Svinka ${ }^{1}$, Visvaldis Svinka ${ }^{2}$, Liga Dabare ${ }^{3},{ }^{1-3}$ Riga Technical University
}

\begin{abstract}
Kopsavilkums. Analizētas iespējas izmantot apdedzinātu kvartāra mālu porainas granulas ūdens attīrīšanai. Izvēlēti Lažas un Progresa atradṇu māli ar atšḳirīgu ķīmisko un granulometrisko sastāvu un porainības palielināšanai izmantotas koksnes skaidas kā izdegošās piedevas. Sorbcijas aktivitāte noteikta attiecībā uz molekulāriem (jods) un jonogēniem (amonija jons) savienojumiem.
\end{abstract}

Atslēgas vārdi: Latvijas kvartāra māli, porainas granulas, sorbcijas aktivitāte.

\section{IEVADS}

N̦emot vērā arvien pieaugošo apkārtējās vides piesārņojumu ar dažādām vielām - smago metālu savienojumiem, šķ̄ininātājiem u.c., arvien pieaug pieprasījums pēc sorbentiem, filtriem, sorbējošām un filtrējošām membrānām u.tml. Ļoti piemērots materiāls vides attīrīšanas tehnologijāâm ir māls un keramikas materiāli uz māla bāzes. Dabīgiem māliem piemīt īpašība sorbēt dažādus savienojumus [1-4], bet šāda veida sorbējošiem materiāliem piemīt arī trūkums. N̦emot vērā mālu minerālu koloidālo raksturu, ūdens pēc attīrīšanas ar māliem iegūst cita veida piesārņojumu - tas satur koloidālās māla daḷiņas, tādēḷ nepieciešami papildus tehnoloǵiskie procesi ùdens attīrīšanai. Šo trūkumu palīdz novērst apdedzinātas mālu keramikas izmantošana ūdens attīrīšanas tehnoloǵijās. Literatūrā atrodams ļoti daudz materiālu par keramikas materiālu izmantošanu smago metālu jonu saistīšanai no ūdens šķīdumiem [5-11]. Klasiskajā keramikas tehnolog̣ijā ir labi zināms, ka, apdedzinot keramikas materiālus, to porainība un materiāla īpatnējā virsma samazinās. Tātad samazinās arī keramikas materiāla iespējamā sorbcijas spēja. Mūsdienās ir zināmi daudzi pañēmieni, kā palielināt apdedzināmā materiāla porainību. Visbiežāk tiek izmantoti dažādi vieglāk pieejami organiskas izcelsmes materiāli. Keramikas materiālu porainības palielināšanai izmantojamās vielas bieži ir dažādu ražošanas nozaru blakusprodukti vai atkritumi, piem., koksnes skaidas, kafijas biezumi, salmi, graudu sēnalas, papīrs, u.c. N̦emot vērā konkrēto izmantojamo mālu sastāvu un īpašības, iespējams izvēlēties konkrētu izejvielu maisījuma sastāvu, keramikas apdedzināšanas temperatūru, temperatūras celšanas àtrumu, lai iegūtu materiālu ar iespējami lielāko porainību un īpatnējo virsmu.

\section{MATERIĀLI UN METODES}

Darbā izmantoti divu dažādu Latvijas reǵionu kvartāra māli - Lažas māli no Kurzemes Aizputes novada un Progresa māli no Zemgales Ozolnieku novada Lielupes labajā krastā. Progresa atradnes mālus izmanto AS „Lode" Ānes ražotnē siltumizolējošo „Keraterm” bloku ražošanai. No plastiskām abu pētīto mālu masām ar 3 masas \% koksnes skaidu piedevu (skaidu diametrs $\leq 2 \mathrm{~mm}$ ) ar ekstrūzijas pan̄ēmienu veidotas mālu granulas ar diametru 4,5 mm. Granulas pēc izžāvēšanas apdedzinātas $700,800,900$ un $1050^{\circ} \mathrm{C}$ temperatūrās. Temperatūras celšanas àtrums krāsnī $300^{\circ} \mathrm{C} / \mathrm{h}$, izturēšanas laiks apdedzināšanas temperatūrā $1 \mathrm{~h}$. Apdedzināšanas temperatūras izvēlētas saskaṇā ar izmantoto mālu diferenciālās termiskās analīzes rezultātiem [12].

Granulu fāžu sastāva raksturošanai izmantota rentgena staru difrakcijas analīze (rentgendifraktometrs Rigaku Ultima +, Japāna), CuK $\alpha$ starojumu un skenēšanas ātrumu $2 \%$ min. Poru izmēru sadalījums, porainība un īpatnējā virsma noteikta ar dzīvsudraba porozimetrijas (Quantachrome Instrument, ASV) un slāpekḷa adsorbcijas (BET) metodi (NOVA 1200e, Quantachrome instrument). Iegūto keramikas granulu sorbcijas spēja noteikta attiecībā uz molekulāriem savienojumiem (jods) un savienojumiem ar jonu saiti (amonija jons). Izmantoti $0,01 \mathrm{n}$ joda un $0,03 \mathrm{n} \mathrm{NH}_{4} \mathrm{OH}$ šķīdumi. Pārbaudes veiktas ar ķīmiskās analīzes metodēm. Sorbētā joda daudzuma noteikšanai izmanto tiosulfăta metodi, kur indikators ir cietes šķīdums. Sorbētā amonija jona daudzumu nosaka, titrējot ar sālsskābi, indikators metilsarkanais. Mērījumi veikti atkarībā no sorbcijas laika, noteikšanu izdarot pēc 1, 2, 3, utt. līdz 20 dienām.

\section{EKSPERIMENTĀLĀ DAḶA UN REZULTĀTU IZVĒRTĒJUMS}

Lažas māli satur nelielu smilšu un putekḷu frakciju daudzumu, tāpēc tie ir ļoti plastiski. Savukārt Progresa māli satur ievērojami lielāku smilšu un putekļu frakciju daudzumu. Sevišķi atšķirīgs ir putekl̦u frakcijas daudzums - Progresa mālos tas ir gandrīz trīs reizes lielāks. N̦emot vērā abu mālu atšķirīgo granulometrisko sastāvu, plastiskas masas sagatavošanai izmantots atšķirīgs iejaucamā ūdens daudzums. Abu pētīto mālu granulometriskais sastāvs parādīts 1.tabulā.

\section{TABULA}

LAŽAS UN PROGRESA MĀLU GRANULOMETRISKAIS SASTĀVS (MASAS \%)

\begin{tabular}{|c|c|c|}
\hline \multirow{2}{*}{ Mālu frakcijas } & \multicolumn{2}{|c|}{ Mālu atradnes } \\
\cline { 2 - 3 } & Laža & Progress \\
\hline Smiltis, $\varnothing>0,05 \mathrm{~mm}$ & 3,39 & 8,45 \\
\hline Putekḷi, $\varnothing 0,05-0,005 \mathrm{~mm}$ & 14,31 & 46,88 \\
\hline Mālainā frakcija, $\varnothing<0,005 \mathrm{~mm}$ & 82,30 & 44,67 \\
\hline
\end{tabular}

Ķīmiskā sastāva ziṇā abi māli atšķiras galvenokārt ar alumīnija oksīda un dzelzs oksīda saturu, kā arī kalcija un magnija oksīdu summāro saturu, par ko liecina arī atšķirīgie masas zudumi karsējot mālus $1000^{\circ} \mathrm{C}$ temperatūrā. Lažas un Progresa mālu ķīmiskais sastāvs parādīts 2.tabulā. 


\section{TABULA}

LAŽAS UN PROGRESA MĀLU ĶĪMISKAIS SASTĀVS (MASAS \%)

\begin{tabular}{|c|c|c|}
\hline Oksīdi & Lažas māli & Progresa māli \\
\hline $\mathrm{SiO}_{2}$ & 46,43 & 51,82 \\
\hline $\mathrm{Al}_{2} \mathrm{O}_{3}$ & 18,74 & 14,69 \\
\hline $\mathrm{Fe}_{2} \mathrm{O}_{3}$ & 7,06 & 5,47 \\
\hline $\mathrm{CaO}$ & 6,62 & 8,27 \\
\hline $\mathrm{MgO}$ & 3,25 & 2,52 \\
\hline $\mathrm{TiO}_{2}$ & 0,59 & 0,59 \\
\hline $\mathrm{K}_{2} \mathrm{O}$ & 3,62 & 3,35 \\
\hline $\mathrm{Na}_{2} \mathrm{O}$ & 0,41 & 0,53 \\
\hline $\begin{array}{c}\text { Karsēšanas zudumi } \\
1000{ }^{\circ} \mathrm{C}\end{array}$ & 9,64 & 10,02 \\
\hline
\end{tabular}

Abu mālu mineraloǵiskais sastāvs ir līdzīgs - galvenais mālu minerāls ir illīta tipa hidrovizlas un neliels daudzums kaolinīta, kuri veido mālu frakciju. Piemaisījumus mālos veido kvarcs smilšu veidā (galvenokārt smilšu frakcijā un daḷēji arī putekḷu frakcijā), kalcīts un neliels kālija laukšpata (mikroklīna) daudzums, kuri sastopami putekḷu frakcijā.

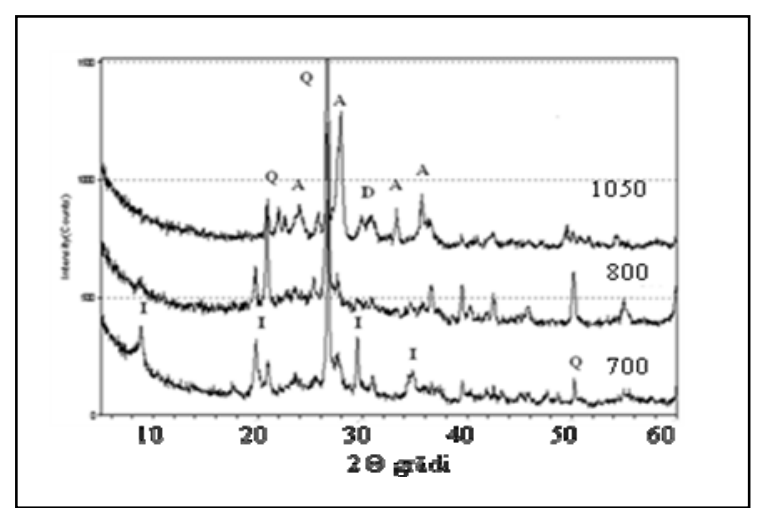

1.att. Dažādās temperatūrās apdedzinātu Lažas mālu granulu difraktogrammas: Q - kvarcs, I - illīts, A - anortīts, D - diopsīds.

Rentgena staru difraktogrammas Lažas un Progresa māliem norāda uz dolomīta klātbūtni. Difrakcijas līnijas šo mālu dažādās temperatūrās apdedzināto paraugu rentgena staru fāžu analīze liecina par apdedzināšanas laikā notikušo termoḳīmisko procesu rezultātiem. Difraktogrammas parādītas Lažas mālu paraugiem 1.attēlā un Progresa mālu paraugiem 2.attēlā. Rezultātu analīze rāda, ka $700^{\circ} \mathrm{C}$ un $800^{\circ} \mathrm{C}$ temperatūrā apdedzinātos paraugos vēl ir saglabājušās illīta difrakcijas līnijas. Arī $900^{\circ} \mathrm{C}$ temperatūrā apdedzinātu granulu difraktogrammās vēl redzamas mazas intensitātes illìta difrakcijas līnijas, bet $1050^{\circ} \mathrm{C}$ apdedzinātās granulās bez kvarca, kura difrakcijas līnijas saglabājas visās apdedzināšanas temperatūrās, parādās jaunu kristālisko fāžu difrakcijas līnijas. No mālu minerālu, dolomīta un kalcīta termiskās sadalīšanās produktiem izveidojušās 2 jaunas kristāliskās fāzes: anortīts (kalcija laukšpats) un diopsīds (kalcija un magnija silikāts).
Granulās bez kristāliskajām fāzēm ir arī poras, kas radušās, sadegot organiskajām piedevām, sadaloties karbonātiem un sablīvējoties materiālam.

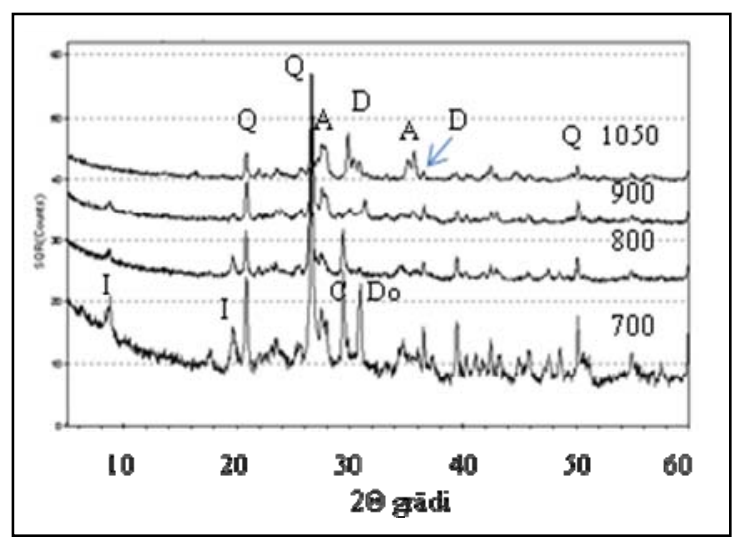

2.att. Dažādās temperatūrās apdedzinātu Progresa mālu granulu difraktogrammas: Q - kvarcs, I - illīts, C - kalcīts, Do - dolomīts, D diopsīds, A - anortîts.

Poru struktūras analīze pēc dz̄ivsudraba porozimetrijas rezultātiem uzrāda būtiskas abu mālu granulu atšķirības. Lažas mālu granulās ir viens dominējošais poru izmērs, kurš, paaugstinot apdedzināšanas temperatūru līdz $900^{\circ} \mathrm{C}$, pārvietojas lielākā izmēra poru virzienā, bet granulās, kuras apdedzinātas $1050^{\circ} \mathrm{C}$ temperatūrā, izzūd šis dominējošais poru izmērs un parādās poras nanoizmēru diapazonā. Visā apdedzināšanas temperatūru diapazonā ievērojami samazinās poru tilpums. Savukārt Progresa mālu granulu gadījumā $700^{\circ} \mathrm{C}$ un $800^{\circ} \mathrm{C}$ temperatūrās apdedzinātām granulām nav raksturīgs kāds noteikts dominējošais poru izmērs, bet tās ir mazākas par $1 \mu \mathrm{m} .900$ un $1050^{\circ} \mathrm{C}$ temperatūrās apdedzinātās granulās parādās dominējošs poru izmērs $0,4-0,2 \mu \mathrm{m}$ rajonā. Salīdzinot ar Lažas mālu granulām, Progresa mālu granulās poru tilpums ir neliels $0,90 \mathrm{~cm}^{3} / \mathrm{g}\left(700^{\circ} \mathrm{C}, 3 \mathrm{a}\right.$ att.), un tas samazinās, paaugstinot apdedzināšanas temperatūru līdz $0,35 \mathrm{~cm}^{3} / \mathrm{g}\left(1050^{\circ} \mathrm{C}\right.$, 3.c att.). Dzīvsudraba porozimetrijas rezultāti apkopoti 3.tabulā, bet ar slāpekḷa adsorbcijas metodi nanoporu anal̄̄zei iegūtie rezultāti parādīiti 4.tabulā.

Kā liecina materiāla poru struktūras pētījumi, izmantojot dzīvsudraba porozimetriju (3.tabula), Progresa mālu granulu porainība ir ievērojami lielāka nekā Lažas mālu granulu porainība visās apdedzināšanas temperatūrās. Sevišķi liela atšksirība abu mālu granulu porainības lielumos ir augstākās temperatūrās apdedzinātam materiālam. Ja treknajam Lažas mālam ar ļoti augstu mālainās frakcijas saturu porainība samazinās no $\sim 15 \%$ līdz $\sim 5 \%$, tad smilšainajiem Progresa māliem tā ir $18-22 \%$ robežās visā apdedzināšanas temperatūru intervālā. Vidējais poru diametrs Progresa mālu granulās ir apmēram 2 reizes lielāks nekā Lažas mālu granulās, bet īpatnējās virsmas lielums savukārt, tieši pretēji, ir apmēram divas reizes mazāks nekā Lažas mālu granulām. 
3.TABULA

DZĪVSUDRABA POROZIMETRIJAS REZULTĀTI

\begin{tabular}{|c|c|c|c|c|c|c|c|c|}
\hline \multirow{2}{*}{$\begin{array}{c}\text { Tempera- } \\
\text { tūra, }{ }^{\circ} \mathrm{C}\end{array}$} & \multicolumn{4}{|c|}{ Progresa mālu granulas } & \multicolumn{4}{c|}{ Lažas mālu granulas } \\
\cline { 2 - 9 } & $\begin{array}{c}\text { Porain̄iba, } \\
\%\end{array}$ & $\begin{array}{c}\text { Škiet. blī- } \\
\text { vums, } \mathrm{g} / \mathrm{cm}^{3}\end{array}$ & $\begin{array}{c}\text { Ipatn. } \\
\text { virsma, } \mathrm{m}^{2} / \mathrm{g}\end{array}$ & $\begin{array}{c}\text { Vid.dia- } \\
\text { metrs,nm }\end{array}$ & $\begin{array}{c}\text { Porainība, } \\
\%\end{array}$ & $\begin{array}{c}\text { Škiet. blī- } \\
\text { vums, } \mathrm{g} / \mathrm{cm}^{3}\end{array}$ & $\begin{array}{c}\text { Ipatn. } \\
\text { virsma, } \mathrm{m}^{2} / \mathrm{g}\end{array}$ & $\begin{array}{c}\text { Vid.diametrs, } \\
\mathrm{nm}\end{array}$ \\
\hline 700 & 18,02 & 1,06 & 12,29 & 80 & 15,27 & 0,76 & 30,68 & 40 \\
\hline 800 & 21,81 & 1,12 & 9,32 & 120 & 14,15 & 0,73 & 16,21 & 70 \\
\hline 900 & 20,50 & 0,98 & 3,63 & 340 & 12,04 & 0,74 & 6,07 & 170 \\
\hline 1050 & 20,66 & 1,06 & 1,56 & 710 & 4,79 & 0,86 & 2,67 & 140 \\
\hline
\end{tabular}

4.TABULA

SLĀPEKḶAA ADSORBCIJAS REZULTĀTI

\begin{tabular}{|c|c|c|c|c|c|c|}
\hline \multirow{2}{*}{$\begin{array}{l}\text { Tempe } \\
\text {-ratūra, } \\
{ }^{\circ} \mathrm{C}\end{array}$} & \multicolumn{3}{|c|}{ Progresa māli } & \multicolumn{3}{|c|}{ Lažas māli } \\
\hline & $\begin{array}{c}\text { Poru til- } \\
\text { pums, } \mathrm{cm}^{3} / \mathrm{g}\end{array}$ & İpatnējā virsma, $\mathrm{m}^{2} / \mathrm{g}$ & $\begin{array}{l}\text { Vidējais poru } \\
\text { rādiuss, nm }\end{array}$ & $\begin{array}{c}\text { Poru tilpums, } \\
\mathrm{cm}^{3} / \mathrm{g}\end{array}$ & $\begin{array}{c}\text { Ippatnējā virsma, } \\
\mathrm{m}^{2} / \mathrm{g}\end{array}$ & $\begin{array}{l}\text { Vidējais poru } \\
\text { rādiuss, nm }\end{array}$ \\
\hline 700 & 0,001 & 0,49 & 1,64 & 0,07 & 24,74 & 1,80 \\
\hline 800 & 0,01 & 4,82 & 1,80 & 0,02 & 7,23 & 1,80 \\
\hline 900 & 0,003 & 1,22 & 2.29 & 0,003 & 1,48 & 1,63 \\
\hline 1050 & 0,002 & 0,69 & 1,64 & 0,001 & 0,05 & 4,14 \\
\hline
\end{tabular}

Salīdzinot abu mālu granulu poru struktūras pētījumu rezultātus nanometru diapazonā, kas noteikti ar slāpekḷa adsorbcijas metodi (4.tabula), kopējā likumsakarība ir līdzīga, bet atškirība vērojama $1050^{\circ} \mathrm{C}$ temperatūrā apdedzinātu granulu gadījumā: īpatnējā virsma Lažas mālu granulās ir apmēram 10 reizes mazāka nekā Progresa mālu granulās. Savukārt vidējais poru rādiuss nanometru diapazonā Lažas mālu granulās ir vairāk nekā divas reizes lielāks par poru rādiusu Progresa mālu granulās. Šie iegūtie rezultāti arī raksturo atškirīgo mālu saķepšanas procesu dažāda granulometriskā mālu sastāva gadījumā.

3. attēlā parādīts ar dzīvsudraba porozimetriju noteiktais poru izmēru sadalījuma salīdzinājums Lažas un Progresa mālu granulās dažādās apdedzināšanas temperatūrās. $700^{\circ} \mathrm{C}$ temperatūrā apdedzinātās granulās (3.a att.) Lažas māliem ir izteikts raksturīgs poru izmērs $0,05 \mu \mathrm{m}$ (50 nm), kamēr Progresa mālu granulām poru diametrs ir mazāks par $0,1 \mu \mathrm{m}$ $(100 \mathrm{~nm}) .800^{\circ} \mathrm{C}$ temperatūrā apdedzinātās abu mālu granulās nav viena raksturīga poru izmēra, bet tas ir robežās no 0,15 līdz $0,01 \mu$ Lažas māliem un mazāks par $0,4 \mu \mathrm{m}$ Progresa māliem. Izteikts raksturīgs poru izmērs ir $900^{\circ} \mathrm{C}$ (3.b.att.) temperatūrā apdedzinātam Lažas mālu granulām, bet tas pārvietojas lielākā poru izmēra virzienā. Progresa mālu gadījumā šajā temperatūrā apdedzinātām granulām izteiktāks poru izmērs ir $0,6 \mu \mathrm{m}$. Pilnīgi atšķirīgs poru izmēru sadalījums ir $1050^{\circ} \mathrm{C}$ temperatūrā apdedzinātām abu mālu granulām (3. c.att.). Lažas mālu granulās poru izmēri ir < $0,02 \mu$, bet Progresa mālu granulās tie ir $4-0,1 \mu \mathrm{m}$.

Lažas mālu granulu sorbcijas spējas noteikšanas rezultāti atkarībā no izturēšanas laika joda šķ̄īdumā liecina, ka 700 un $800^{\circ} \mathrm{C}$ temperatūrā apdedzinātas granulas 1 dienas laikā adsorbē lielāko daḷu (apm. 90 \%) no visa šķīidumā esošā joda daudzuma (4.att.). Palielinot izturēšanas laiku šķ̄īumā, adsorbētais joda daudzums palielinās un pēc 4 diennakšu izturēšanas granulas ir adsorbējušas visu šķīdumā esošo jodu.
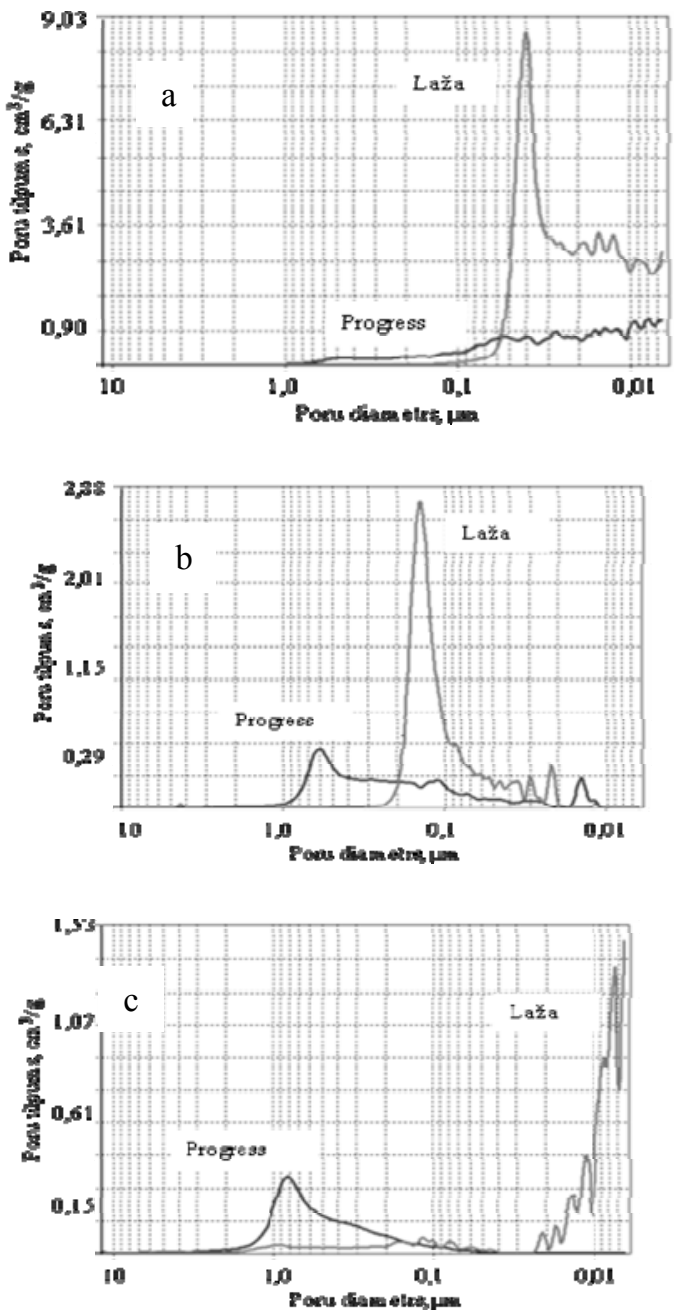

3.att. Poru izmēru sadalījums $700^{\circ}$ (a), $900^{\circ}$ (b) un $1050^{\circ} \mathrm{C}(\mathrm{c})$ temperatūrās apdedzinātām Lažas un Progresa mālu granulām. 
$900^{\circ} \mathrm{C}$ temperatūrā apdedzinātās granulās joda adsorbcijas ātrums samazinās un viss jods tiek adsorbēts 7 dienu laikā. $1050^{\circ} \mathrm{C}$ temperatūrā apdedzinātas granulas adsorbē jodu vēl lēnāk un pēc 9 dienām ir adsorbēts $89 \%$ šksīdumā esošā joda.

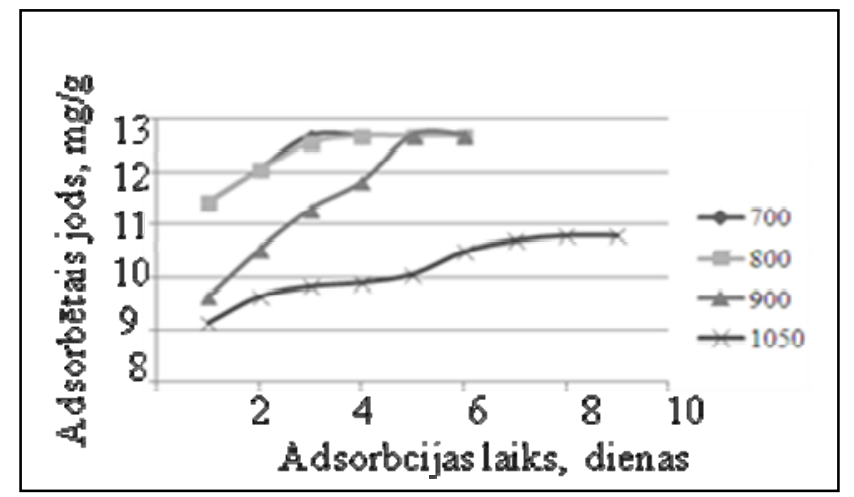

4.att. Joda adsorbcija no 0,01 n šks̄iduma ar dažādās temperatūrās apdedzinātām Lažas mālu granulām.

Nedaudz līdzīga adsorbcijas aina redzama Progresa mālu granulām. 6 dienās viss šḳīdumā esošais jods ir adsorbējies uz $700-900^{\circ} \mathrm{C}$ temperatūrā apdedzinātām granulām (5.att.). Savukārt $1050^{\circ} \mathrm{C}$ temperatūrā apdedzinātas granulas 4 dienu laikā adsorbē 70 \% no šķ̄īdumā esošā joda daudzuma. Pat pēc 21 dienas tās ir adsorbējušas tikai $76 \%$ joda.

Salīdzinot adsorbcijas spēju vienādos apstākḷos apdedzinātām granulām ar atškiirīgiem Latvijas kvartāra māliem, redzams, ka nav viennozīmīgs rezultāts visās apdedzināšanas temperatūrās. 700 un $900^{\circ} \mathrm{C}$ temperatūrā apdedzinātām granulām lielāka adsorbcijas spēja ir Progresa mālu, bet 800 un $1050^{\circ} \mathrm{C}$ temperatūrā apdedzinātām granulām tā ir lielāka Lažas mālu gadījumā. 6. un 7.attēlā parādīts šo rezultātu salīizinājums.

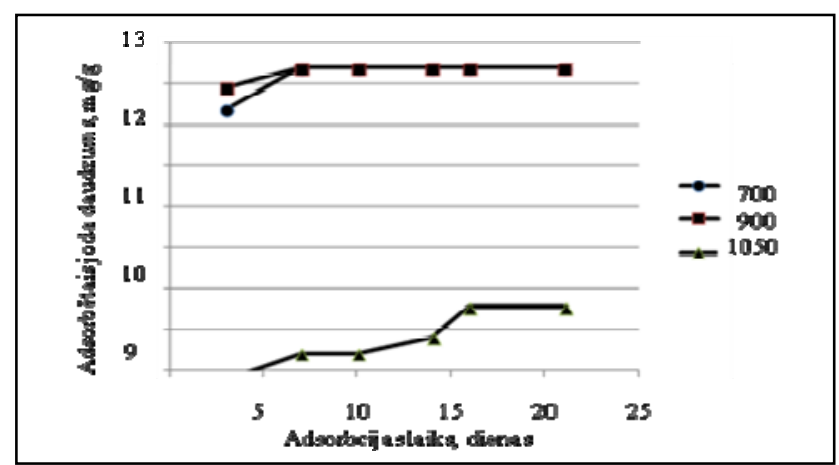

5.att. Joda adsorbcija no 0,01 n šksiduma ar dažādās temperatūrās apdedzinātām Progresa mālu granulām.

Paaugstinot granulu apdedzināšanas temperatūru, adsorbētā joda daudzuma atšķirība palielinās, kas liecina par mālu granulometriskā sastāva ietekmi un keramikas materiāla īpašībām. $\quad 700^{\circ} \mathrm{C}$ temperatūrā apdedzinātām granulām adsorbcijas ātrums ir atškirīgs, pie kam lielāks tas ir liesāko Progresa mālu granulām (6.att.) un tikai pēc 9 dienām tas kḷūst vienāds. Savukārt $1050^{\circ} \mathrm{C}$ apdedzināta materiāla gadījumā uz Lažas mālu granulām adsorbētais joda daudzums ir lielāks un tas saglabājas neatkarīgi no sorbcijas ilguma (7.att.).

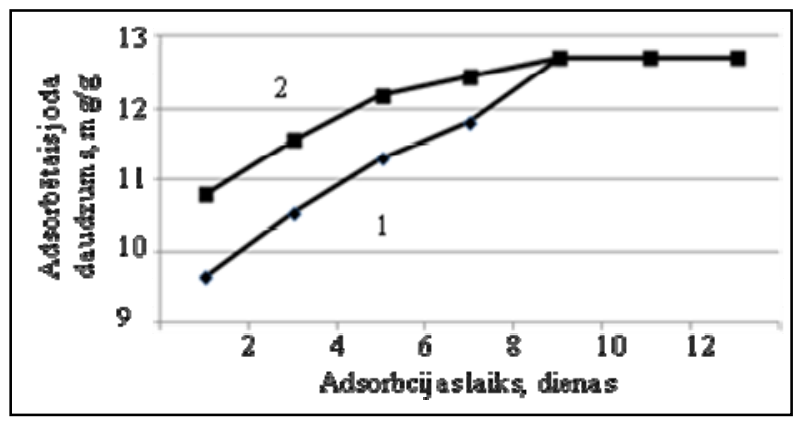

6.att. $700^{\circ} \mathrm{C}$ temperatūrā apdedzinātu Lažas un Progresa mālu joda adsorbcijas salīizinājums: 1- Laža; 2- Progress.

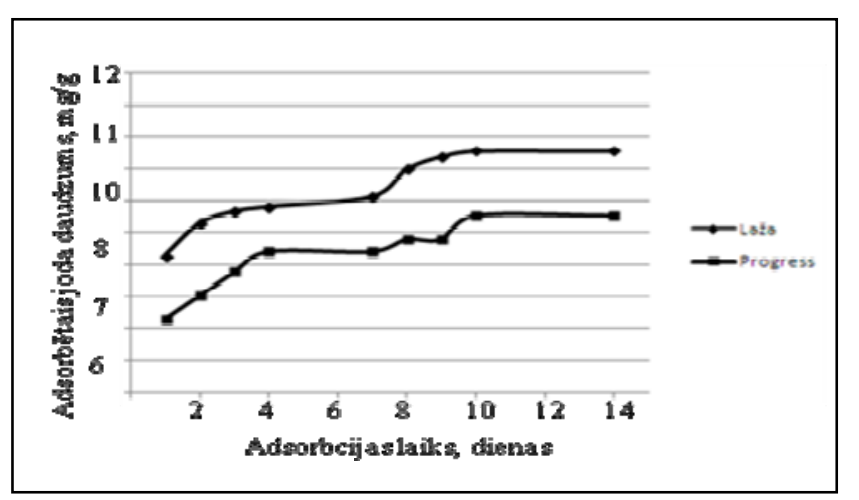

7.att. $1050^{\circ} \mathrm{C}$ temperatūrā apdedzinātu Lažas un Progresa mālu joda adsorbcijas salīdzinājums.

Amonija jona adsorbcijas spējas izmaina atkarībā no apdedzināšanas temperatūras un sorbcijas laika ir atšķirīga, salīdzinot ar joda adsorbciju. Lažas mālu gadījumā vislielākā sorbcijas spēja ir 800 un $1050^{\circ} \mathrm{C}$ temperatūrā apdedzinātiem paraugiem (8.att.), pie kam tas nepārsniedz 0,22-0,26 mg/g, tas ir, 15 dienu laikā keramikas granulas adsorbē 2,4\% no šķīdumā esošā amonija jona. 700 un $900^{\circ} \mathrm{C}$ temperatūrā apdedzinātas granulas adsorbē vēl mazāk amonjaka, tikai 0,5 $1,0 \%$ no šksīiumā esošā amonjaka.

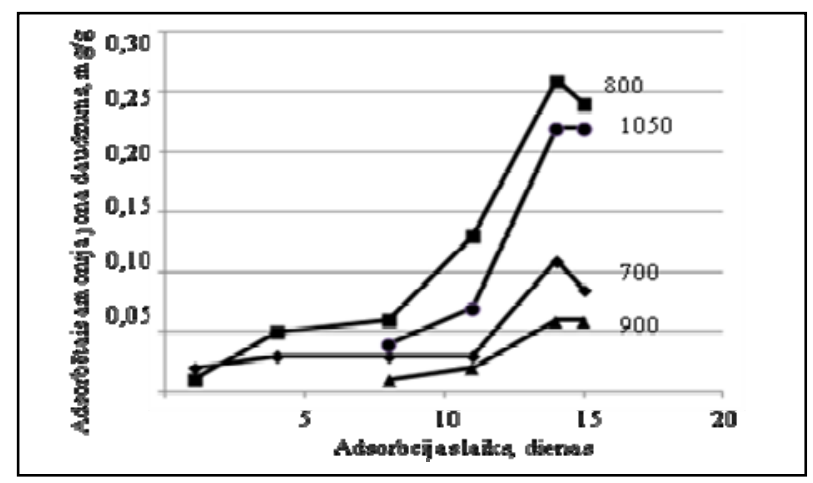

8.att. Amonija adsorbcija uz dažādās temperatūrās apdedzinātu Lažas mālu granulām no $0,03 \mathrm{n}$ amonjaka šķīduma

Apskatot amonija sorbciju Progresa mālu granulās (9.att.), redzams, ka to sorbcijas spēja $1050^{\circ} \mathrm{C}$ temperatūrā apdedzinātām granulām ir līdz $0,06 \mathrm{mg} / \mathrm{g}$, kas nepārsniedz 1,5 \% no šḳīdumā esošā amonija jona daudzuma. Pārējās temperatūrās apdedzinātas granulas amonjaku praktiski 
neadsorbē. Šāds rezultāts varētu būt saistīts ar granulometriskā sastāva ziṇā atškikirīgu kvartāra mālu keramikas struktūru.

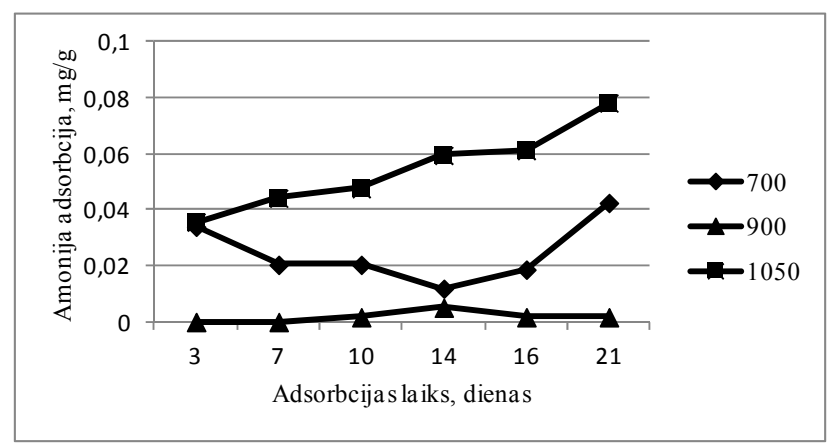

9.att. Amonija adsorbcija uz dažādās temperatūrās apdedzinātām Progresa mālu granulām no $0,03 \mathrm{n}$ amonjaka šḳīduma.

Salīdzinot un analizējot iegūtos rezultātus un ņemot vērā adsorbējamo vielu rādiusus: nehidratēta $\mathrm{NH}_{4}^{+}$jona rādiuss ir $0,143 \mathrm{~nm}$, bet $\mathrm{J}_{2}$ molekulas rādiuss $0,133 \mathrm{~nm}$, redzams, ka abu jonu salīdzinošā sorbcijas aktivitāte ir ievērojami atškirīga. Tam varētu būt divi iemesli. Pirmkārt, hidratēta amonija jona rādiuss ir ievērojami lielāks par nehidratēta jona rādiusu, tāpēc tā saistīšanās uz poru virsmas ir iespējama mazākā mērā. Otrkārt, sorbcijas procesu ietekmē granulu radītās šksīduma $\mathrm{pH}$ izmainas $-700-900^{\circ} \mathrm{C}$ temperatūrā apdedzinātas granulas rada bāzisku vidi, bet labākā amonija jona sorbcija ir $1050^{\circ} \mathrm{C}$ temperatūrā apdedzinātām granulām, kuras rada šksidrumā neitrālu vidi. Kopumā labāku sorbcijas aktivitāti uzrāda keramikas granulas, kas iegūtas no kvartāra māliem ar lielu mālu frakcijas saturu, t.i., Lažas atradnes māliem.

\section{SECINĀJUMI}

Latvijas kvartārie māli ir izmantojami porainu keramikas granulu ražošanai, kas ir izmantojamas piesārņota ūdens attīrīšanai. Granulu sorbcijas aktivitāti nosaka gan pašu izmantoto kvartāra mālu ķīmiskais un granulometriskais sastāvs, gan granulu apdedzināšanas temperatūra. Apdedzināšanas procesā materiālā rodas ievērojams daudzums nanoizmēra poru, un to īpatnējās virsmas lielums ir svarīgs rādītājs, kas nosaka materiāla sorbcijas spēju. Sorbcijas process ir atkarīgs no ķīmiskās saites veida piesārņojošajā vielā, no piesārņojošās vielas molekulas vai jona izmēriem un no šksīduma $\mathrm{pH}$, kura izmaiņas rada karbonātu sadalīšanās apdedzinot granulas $700-900^{\circ} \mathrm{C}$ temperatūrās. Sorbcijas aktivitāte attiecībā uz savienojumiem ar molekulāro saiti nav atkarīga no šksīduma $\mathrm{pH}$, bet gan no nanoizmēra poru virsmas laukuma. Sorbcijas aktivitāti attiecībā uz savienojumiem ar jonu saiti bez poru virsmas lieluma ietekmē arī šķ̄īduma $\mathrm{pH}$.

\section{IZMANTOTĀ LITERATŪRA.}

[1] Švinka, R., Švinka, V., Pētersone, E. Latvijas mālu sorbcijas īpašības un to izmantošana ūdens attīrī̌sanai. Latvijas Ķīmijas žurnāls, 1994, Nr. 3, 280. - 285. lpp.

[2] Gupta, S.S., Bhattacharyya, K.G. Interaction of metal ions with clays: I. A case study with Pb(II). Applied Clay Science, 2005, vol. 30, pp. 199 - 208. http://dx.doi.org/10.1016/j.clay.2005.03.008

[3] Svinka, R., Petersone, E., Cimmers, A., Svinka, V. Sorption process in the illite type Latvian clays and thermal binding of heavy metal ions. Materials of Intern. Conf., Lithuania. "Technology of Silicate", Kaunas, 1998, pp. $13-16$.

[4] Abu-Eishah, S.I. Removal of $\mathrm{Zn}, \mathrm{Cd}$ and $\mathrm{Pb}$ ions from water by Sarooj clay. Applied. Clay Science, 2008, vol. 42, pp. 201 - 205. http://dx.doi.org/10.1016/j.clay.2008.02.003

[5] Švinka, A., Cimmers, A., Švinka, V. Smago metālu jonu saistības pakāpe keramiskos materiālos. Neorganiskie stikli, pārkläjumi un materiāli, RPI izdevn., Rīga, 1991., 98. - 103.lpp. (krievu val.)

[6] Sedmale, G., Šperberga, I., Hmeḷovs, A., u.c. Dabas aizsardzībai motivēti keramikas materiāli, pielietojot Latvijas minerālās izejvielas. RTU Ziātniskie raksti. Materiālzinātne un lietišşāa ķīmija, 2009, 19. sējums; 8. - 87. lpp.

[7] Priyantha, N., Bandaranayaka, A. Investigation of kinetics of $\mathrm{Cr}(\mathrm{VI})$ fired brick clay interaction. J. Hazard. Mater., 2011, No.188, pp.193 197. http://dx.doi.org/10.1016/j.jhazmat.2011.01.090 Blūms, A., Kampars, V. Svina jonu adsorbcija uz apdedzinātām māla lodītēm no ūdens šķīdumiem. RTU Zinātniskie raksti, Materiālzinātne un lietiškşā kìmija, 2007, 15. sējums, 48. - 50. lpp.

[8] Boonamnuayvitaya, V., Chaiya, C., Tanthapanichakoon W., et.al. Removal of heavy metals by adsorbent prepared from pyrolyzed coffee residues and clay. Sep. Purif. Technol., 2004, No. 35, pp.11- 22.

[9] Khazali, O., Abu-El-Halawa, R., Al-Shou'od K. Removal of copper(II) from aqueous solutions by Jordanian pottery materials. J. Hazard. Mater, 2007, No.139, pp.67-71.

[10] Labidi, N.S. Removal of mercury from aqueous solutions by waste brick. Int. J. Environ. Res., 2008, vol.2 (3), pp.275 - 278. http://dx.doi.org/10.1016/j.jhazmat.2006.06.005

[11] Švinka, V., Bidermanis, L., Švinka, R., u.c. Termoķīmiskas reakcijas mālu minerālos šūnu keramikas iegūšanai. RTU Zinātniskie raksti, Materiālzinātne un lietišşā ķīmija, 2011, 24. sējums, 56.-60. lpp.

Ruta Svinka, Dr.sc.ing. (1993) RTU. Leading researcher in Riga Technical University Faculty of Material Science and Applied Chemistry Institute of Silicate Materials. Author of upwards 90 scientific works and 8 patents in the field of silicate materials and technical ceramic. The Member of American Ceramic Society, the Member of board of Latvian Materials Research Society Phone: +37167615560, e-Mail svinka@ktf.rtu.lv

Visvaldis Svinka, Dr.sc.hab.ing. (1997) RTU. Assoc.prof., leading researcher in Riga Technical University Faculty of Material Science and Applied Chemistry Institute of Silicate Materials. Author of upwards 100 scientific works and 16 patents in the field of silicate materials and technical ceramic. The Member of German Ceramic Society, Member of Scientic Doktorate Concil P-02.

Phone: +37167615560 e-Mail: svinka@ktf.rtu.lv

Liga Dabare, B.sc. (2012) student in master program, scientific assistant in Riga Technical University Faculty of Material Science and Applied Chemistry Institute of Silicate Materials. Author of 2 scientific publication in field of clay ceramic. Phone: +37128862365, e-Mail dabarel@inbox.lv

\section{Ruta Svinka, Visvaldis Svinka, Liga Dabare. Sorption Properties of Ceramic Pellets Produced from Quaternary Clays}

Porous ceramic pellets from Latvian clays were investigated for the purification of wastewater. In the research, two Quaternary clays of deposits Laza and Progress were used with different chemical compositions and grain size distributions. Sawdust as combustible additive was used for the enlargement of pellet porosity. Pellets were fired at $700,800,900$ and $1000^{\circ} \mathrm{C}$ temperature. Thermal analysis, X-ray phase analysis, nitrogen adsorption method (BET) and mercury porosimetry method were used for the characteristics of raw clay and fired materials. Sorption activity of pellets was determined concerning substances with molecular and ionic bond during 14 days. The type of clay and firing temperature influences the sorption time. Large number of nano-size pores is formed during the sintering process of clays, and the specific surface area of pores determines the sorption activity. Pellets fired at $700-900^{\circ} \mathrm{C}$ had the best sorption activity concerning iodine. All amount of iodine is adsorbed during 4 days on the Laza clay pellets, but on the Progress clay pellets during 7 days. Sorption activity of substance with 
ionic bond (ammonia ion) was small and the best sorption ability was shown by the pellets of Laza clay fired at the temperature of $1050{ }^{\circ} \mathrm{C}$. In Quaternary lime rich clay pellets as a result of thermal decomposition of carbonates $\mathrm{pH}$ of solution increases in water medium and influences the sorption of substances with an ionic bond, but sorption of substances with a molecular bond is not influenced. Sorption of inorganic substances from wastewater is a selective property of porous clay ceramics. To produce ceramic materials for wastewater purification, clays with a high content of small grains $(\varnothing<0.005 \mathrm{~mm})$ should be used.

Рута Швинка, Висвалдис Швинка, Лига Дабаре. Сорбционные свойства керамических гранул из четвертичной глины Керамические гранулы из глины Латвии были исследованы с целью применения их для очистки сточных вод. Были использованы четвертичные глины месторождений Лажа и Прогресс с разным химическим и гранулометрическим составом. Для увеличения пористости гранул в качестве выгорающей добавки применялись опилки в количестве 2 вес.\%. Глиняные гранулы обжигались при температурах $700,800,900$ и $1050^{\circ} \mathrm{C}$. Для характеристики глин и обожженных материалов использовались термический анализ, рентгенофазоиый анализ, адсорбция азота (BET) и ртутная порозиметрия. Сорбционная активность была определена по отношению к веществам с молекулярной и ионной связью в продолжительности 14 дней. Сорбционная активность увеличивается в течение времени в зависимости от исходной глины и температуры обжига гранул. Наибольшую сорбционную активность по отношению к йоду имеют гранулы, обожженные при температуре $700-900^{\circ} \mathrm{C}$. На гранулах глины месторождения Лажа весь йод был адсорбирован в течение 4 дней, а на гранулах глины месторождения Прогресс в течении 7 дней. Сорбционная активность гранул по отношению к иону аммония весьма мала, однако она больше на гранулах глин месторождения Лажа, обожженных при температуре $1050^{\circ} \mathrm{C}$. При спекании глин образуется большое количество пор наноразмера с большой удельной поверхностью, что и определяет сорбционную активность. В результате разложения карбонатов при обжиге четвертичной глины эти гранулы увеличивают щелочность водной среды и влияют на сорбционную активность гранул по отношению к веществам с ионной связью, но не влияют на сорбционную активность по отношению к веществам с молекулярной связью. Сорбционная способность неорганических соединений из сточных вод является селективным свойством пористой керамики, полученной из глины. Глины, содержащие большое количество глинистой фракции с размером зерен менее 0,005мм, являются более пригодным сырьем для производства пористых гранул для очистки сточных вод. 